\title{
An Exploration of the Imperatives for Successful Strategy Execution in ODL Institutions: Some Observations from Southern Africa
}

\author{
Dr C. Shonhiwa, Prof. D Ndudzo (PhD)
}

\begin{abstract}
The study analysed the factors that influence the effectiveness of strategy execution in Open and Distance Learning institutions. The qualitative research methodology was employed with the research design taking a case study approach. Primary data were gathered through interviews and direct and participant observation methods. The study also utilized secondary data from journal publications mainly focusing on the area of strategy execution. The research population was composed of management in ODL universities in the $S A D C$ region. Respondents to the interviews were selected from ODL Universities in three SADC countries using the simple random sampling technique. The highest levels of confidentiality and ethical standards were adhered to so as to protect the integrity of the respondents and that of the Universities. The study revealed that strategy execution could be enhanced through the following; identification of institutional competences, translate strategy into explicit implementation guidelines, adapt to rapidly changing conditions, knowledgeable and engaged leadership, prudential use of resources and worker buy-in.
\end{abstract}

\section{Introduction}

A strategic plan is a document that clearly focuses an organisation in a chosen direction and energises and moves the institution towards the achievement of a stated vision of the organisation. The strategic plan document should also articulate how the resources, skills and time of the organisation would be harnessed and channeled towards the attainment of the goals and objectives of that organisation. The process of operationalising the strategic plan is referred to as strategy execution. Strategy execution is a process that brings together people, strategy and operations. An organisation constructs a strategy, which indicates the direction and scope the organisation seeks to in the short term, medium term and long.

\subsection{Background to the study}

A strategic plan is a framework for decision making and for securing approval and support before an activity is undertaken. It provides the basis for detailed planning, at lower levels in an institution and it can be broken down into annual plans. A strategic plan is a document that can be employed to explain a business concept to others and it assists in benchmarking and monitoring the performance of an institution against that of comparable institutions. A really novel plan can stimulate change and become building blocks of future plans. A strategic plan is a visionary, conceptual and directional document, but it also has to be realistic and attainable. Strategic execution starts from the time strategic planning is started; the planners should wear their strategic thinking hats in order to come up with a product that satisfies what the institution desires to achieve and how that achievement can come about; a strategic plan should be viewed as a guide that focuses time, competences and resources towards a successful management of institutional affairs. A strategic plan not ne a list of recurrent activates, in an incremental manner, but it should contain new insights and ideas that are likely to advance e the achievement of institutional goals and objectives. The new insights result from creative and innovative thinking premised on exploring new possibilities without constraint, exploring the ideas and aligning them with the purpose of the institution.

\subsection{Statement of the problem}

Research has shown that most modern higher education institutions has well defined strategies outlined in ambitious strategic plans, few have, however, achieved desirable success levels. This points to a gap between strategic planning and strategy execution.

\subsection{Research questions}

How can strategy execution be successfully undertaken?

Which factors influence the successful execution of a strategic plan?

\subsection{Purpose of the study}

The purpose of the study is to identify factors that influence strategy execution in ODL institutions of higher learning.

1.6 Significance of the study 
The study is beneficial to open and distance learning institutions of higher education, which are likely to revise the way they have, hitherto, crafted and executed their strategic plans. The higher education institutions play a major part in the socio-economic development of respective countries; therefore receive support by governments through grants. The institutions, however, need to stay relevant by achieving set goals and effectively carrying out their mandates hence the importance of strategy execution.

\subsection{Delimitation}

The study confines itself to the execution of institutional strategic plan in open and distance learning (ODL) institutions of higher education. The ODL institutions studied are from the Southern African Development Community area.

\subsection{Ethical considerations}

The researchers undertook to generate data from participants in an ethical manner. All respondents voluntarily agreed to participate in the study. The researchers undertook to maintain the highest level of confidentiality thereby used pseudonyms where names were needed.

\section{Review of Related Literature}

The review covered an overview of strategic planning process, an implementation section and what other researchers and writers say about strategy execution. The review also covered the factors that affect or influence strategy execution and possible solutions to these factors in order to improve strategy execution.

\subsection{Theoretical Framework}

The Strategic Execution Framework was designed to explain how strategy execution could be undertaken successfully, irrespective of the many pitfalls, myths and challenges advanced by researchers and practitioners alike. Boot (2015) contends that for strategy execution to succeed there has to be deliberate effort focused on deliverables, like the planning, analysing the data, and controlling finances. Collaboration across the institution was also regarded as more important, which could be in teams, functions and institutional units. The accompanying Strategic Execution Framework illustrated the inter-connectedness of collaborative action and the roles that each player was expected to play.

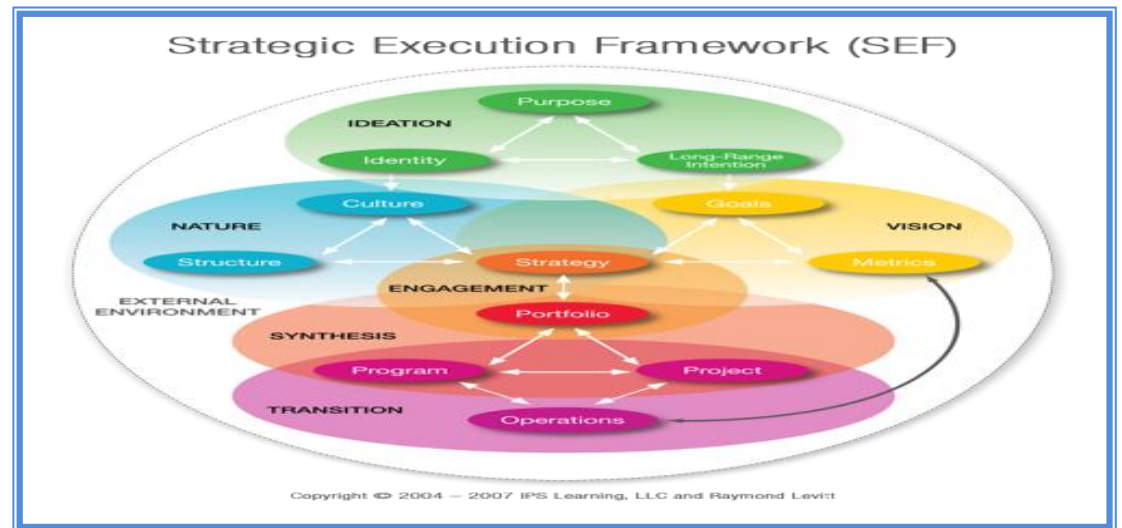

Fig. 1 The inter-connectedness of institutional activity in strategy execution

In a study, Boot (2015) revealed that strategy execution was possible where the practitioners had to successfully deal with an increased rate of change and complexity; where there was the need to absorb disruptive technological developments; where the institution was forced to build agility and complexity in strategy execution; the institution was able to master the dynamics of global markets; where collaboration was undertaken on a cross-institutional and cross-cultural basis; where a new way to change how to navigate shortterm and long-term goals and objectives; and, the institution was faced with new innovative players.

\subsection{Strategic planning challenges}

Heathfield, S (2015) identifies a number of factors that hinder the execution of strategic plans, and some of them were:

\section{Competition effect}

Strategy execution could fail due to a negative change in sales volumes and competition with upgraded products.

\section{Lack of prioritisation}


The lack of prioritisation and the adoption of all activities in equal measure, could lead to strategy execution failure. When all the areas are a priority, the workforce is forced to spread effort over a wide area and end up making baby-steps in a number of ineffectual areas;

\section{Over-consultation}

When institutions work with consultants they may be requested to generate too much data that they may not use in crafting the strategy and end up with weak strategy. The weakness could emanate from too much data which the institution may not have the ability to convert into information for planning purposes; and

\section{Inherent inability to execute strategy}

An institution may fail to create a necessary specific framework for the execution and follow-up of the strategy. A monitoring framework makes it possible to create an accountability system that consists of action items and follow-up plans that enable strategy execution to be successful.Kilic, and Atkuna (2015) carried out a study in which they desired to establish the reasons for institutional failure to execute strategy in Turkish Public Organisations. They started by the premise that the inability to execute strategy was a result of inadequate translation of strategic objectives to employees in an organization, low motivation levels, resistance to change, peer pressure or group influence and the mere prevalence of underperformance. However, the findings of the study were that in Turkish Public Organisations the translation of strategy objectives was perceived to be successful. The perception was that the level of understanding of strategic objectives and the perceived motivation were high, and the other obstacles that they had were not perceived to be influential.

Dunlop, Firth, and Lurie (2013) relate the failure to execute a strategy to what they call "inevitable slump" in enthusiasm, excitement and the general organisational resistance that set in after the crafting of a strategy. This resistance is a result of the lack of skills, competences and knowledge in workers needed to execute the new strategy.According to Dunlop, Firth, and Lurie (2013) the generic approach to strategy execution was administrative in nature; it focused on workforce, time, and a sequence of activities that usher in change. The approach treated strategy execution as a gigantic activity that was broken down into manageable pieces that developed a master plan which detailed the implementation and timed the activities to specific time frames. The administrative approach was attractive to institutions and organisations because it ensured an institution was quickly mobilised as a unit and the certainty of clear time frames was assured.

Favaro, Hirsh and Rangan (2015) believe that many business leaders think they would rather have great strategy execution than a superior strategy, although they tend to also believe one may not have the first without the second. They shift the discussion from the desirability of brilliant strategy execution to a theoretical discussion about whether to have a great strategy or be able to brilliantly execute a poor or average strategy. Brunings (2015) carried out a research on strategy execution and came up with myths on why strategy execution failed. The first myth was that there was poor alignment which led to the failure of strategy execution.Murray, A (2015) says there were three main requirements for a successful execution of strategy. First, there should be clear goals and objectives that support the strategy. The second requirements were that there should be ways of measuring performance and its progress towards the achievement of the goals and objectives, and lastly, the institution should have transparent accountability for performance and progress. Murray (2015) also says that for strategy execution to be successful, there should a systematic manner of exposing reality and acting on the reality, when so exposed.

In the work by Boot (2015) the importance of collaboration was emphasised, and in pursuit of that goal a few suggestions were made. The suggestions were that; the institution had to foster a mindset that encouraged collaborative behaviour in the form of team building, thinking outside the box in functions, culture and in departments; the institution needed to make decisions and prioritise in a manner that created transparent: processes and procedures have to stimulate continuous feedback among people, teams and leaders; the institution needed to have in place a portfolio of integrated technologies that promoted collaboration; and, there had to be a method to measure and establish a balance between learning through analysis and learning through evaluation. An institution that followed the suggested route was most likely to win in strategy execution. Hrebiniak, L.G (2014) says that strategy execution can only be attained through a carefully planned approach, without which no strategic goals and objectives can be attained. The development of such a strategically planned approach was a monumental task and a challenge to management. The approach required the setting of clear priorities and the analysing of data, keeping a rhythm to meetings and evaluating the strategy.

\section{Research Methodology}

The researchers believed that knowledge was a result of social interaction and it was not in existence, waiting to be discovered. In the same vein reality was not given but was a product of social creation and agreement. Because of these facts the researchers adopted the constructivist approach to the study, with an interpretive perspective. The researcher went into institutions of higher education and dialogued with practitioners in order to learn their perceptions of factors that influence the successful execution of strategy. Conversely, the discussion also considered the factors that hinder the successful execution of strategy.The 
qualitative paradigm was chosen for the study because it allowed the researcher to carry out in-depth discussions and analyse institutional documents to establish the nature of strategy execution being carried out. The population was composed of all open and distance learning institutions in the Southern African Development Community (SADC), with an average of one such institution per country.

The researchers considered the institutions in three nations, which were easily accessible. The researchers purposively selected to dialogue with personnel in the managerial position and in administration because these were exposed to issues of strategy formulation, implementation/ execution and monitoring. They were the best people to respond to the questions and contribute fruitfully to the outcome of the study. The researchers engaged participants in an interview and analysed the strategic plans and the progress reports that were produced in each institution. The study engaged participants in an interview and analysed the strategic plans the institutions had in place to determine how they envisaged to execute them, and with what results. Data that were extracted from interviews and document analysis were analysed and interpreted to give meaning. The researchers were guided by the themes that emerged from the data generating process, which were indicators to the factors that the practitioners considered appropriate if strategy execution were to be undertaken successfully. Themes extracted from interviews and document analysis were;

"strategicalignment at various levels of the institution"

"identification of institutional competences"

"proper execution guidelines"

"need for knowledgeable and engaged leadership"

"prudential use of resources, especially monetary resources"

"worker buy-in emanating from involvement and participation in strategy formulation"

"adaptation to changes from implementation"

\section{Findings Of The Study}

The themes that emerge from the data generating process were indicative of the factors that influence the execution of strategy in institutions of higher learning. The factors that were identified in the themes were discussed below.

\section{Identification of institutional competences}

It was evident that strategy execution could not be undertaken without undertaking a competence audit in each institution. The institution needed to know the competences that existed within its workers and what it could do exceptionally well, where it enjoyed comparative advantage. For instance, an institution, like University of South Africa, was competent in tutorials, where it grew its competence in e-learning and hoped to be a paperless university within five years from 2014. An institution needed to prioritise areas of attention in the strategies that it pursues as a short-cut to world class performance.

The institution should start by realising and appreciating the competences within it, by defining those competences, by demonstrating value differently and by continuously evaluating impact through the measurement of output. Momentum could be accelerated through demonstrating value differently from historic demonstrations and the traditional tools of formal training. The identification of institutional competences could be broken down into individual competences before they are aggregated into institutional competences. This would help in the future when hiring new employees or replacing those who leave; an institution could draw up a competence map, where it listed the competences it possessed and where these were located. The competence map could then be employed as a basis for re-alignment of existing employees, moving employees to areas where they performed at their best.

\section{Translate strategy into explicit implementation guidelines and choices}

Dynamic approach addressed the administrative approach shortfalls and started off by articulating the actionable design principles, which divided the direction of the institution to many execution teams. The novelty with dynamic approach was that workers were left with the freedom to be creative and adaptive. The dynamic approach addressed four broad areas of concern. Strategic leadership should be in place to craft actionable design principles. The leaders should be multilingual people with an affinity for operations and strategy crafting. These should play appropriately defined leadership roles, which empower them to make decisions, connect them to senior management and should be present during strategy design periods. The second was the pictures and practices stage, where workers should be able to visualise the desired outcomes and the paths to be used to get there; leadership should be able to provide guidance for team members; and, leadership should be able to validate senior management strategic hypothesis. Third, there should be a line-of-sight metrics, which refers to the establishment $\mathrm{f}$ a clear line of sight between the programme deliverables and strategic ambitions; they should define the outcomes metrics and manage the programme; and leadership should realise that outcome metrics link drivers and leading indicators with strategic outcomes. The last areas considered the traditional tools that senior management used both internally and externally. The tools included the project charters that defined the purpose, objectives and measured success, established structure, decisions and rights and the state of 
operating principles. There should be a stakeholder engagement plan, which illustrated the segmentation of stakeholders and drew up a customised engagement plan. There could also be a centralised communication plan and a synergy plan.

\section{Adapt to rapidly changing conditions}

The dynamic approach no longer treated the execution as a change programme that was managed and "done to" or "pushed through" the institution. It built in mechanisms for learning and course-correcting. It also sought to improve leadership contextual awareness, solicited different perspectives through many collaborative tools, which allowed it to share and test ideas early in the execution stage. Dynamic strategy execution leveraged scenario planning and environmental scanning in order for the institution to be able to anticipate challenges. Dynamic execution places immense value in productive dialogue techniques which facilitated effective collaboration, led to more efficient decision making and formed strong partnerships with key stakeholders. The institution should complement internal resources with external resources and assume a long term perspective and an outward-looking view. In better dialoguing, the institution should engage in mutual learning, translate implicit to explicit assumptions and balance the amount of advocacy with inquiry.

\section{Knowledgeable and engaged leadership}

The institutions should be led by people who were experts in the areas covered by the mandate of the institution. The leadership needed to appreciate the institution's mandate and what it took to attain that mandate, before anything could be expected of them. The leadership should be made up of team players, people who thrived in collaborative performance. The area of collaboration was important in strategy execution because the individual members of the institution worked in semi-specialised areas and that effort, and the result, needed to be aggregated into one whole outcome, which needed collaboration. Engaged leaders were those whole though involvement and participation, who led their charges by example. They showed that they knew what was required of the workforce and they could grease their hands as well, who identified with the workforce, as colleagues. A leader who shunned involvement and the hands-on approach found it difficult to be accepted by employees as one of them. Leaders who were not accepted did not produce results.

\section{Prudential use of resources}

Participants identified the need to efficiently use resources in order for the institution to achieve more output with fewer resources. The way to proceed was to formulate a budget for all the activities the institution would be engaged in, preferably citing the output in each budgetary area. For instance, the items in the budget could be made up of the result that was intended to be achieved so that any purchase would be for input into the production of that targeted product.There were cited cases of monetary defrayments that did not advance the cause of the institution and were not budgeted for, but these were not of a serious nature. What was emphasised was to prevent institutional politics to get into budgetary considerations.

\section{Worker buy-in}

The employees in the institution should identify themselves with the strategy of the institution. One way of achieving this was to involve them so that they participated in the crafting of the strategy. Involvement and participation gave them the feeling that they belonged to the institution and that their voices mattered, and it enabled them to continue to be involved in the monitoring of the performance. A lack of participation and involvement meant that the workforce merely waited for management to give instructions and for them to react to the instruction, which does not contribute to quality performance and motivation.

\section{Conclusion}

Strategy execution is a people dependant function in institutions and hugely depends on the effectiveness of leadership and management styles. Management in organizations should be able to identify competencies of the organization and ensure that they are in-sync with the key success factors of the industry. Adequate resources should be provided and subordinates made to accept and own the goals for successful strategy execution.

\section{References}

[1]. Boot, A (2015). Strategy Execution: Get Collaboration Right!

[2]. http://leadershipwatch-aadboot.com/2015/05/03/strategy-execution-get-collaboration-right/ (Retrieved on 03.07.15)

[3]. Brunings, J (2015). Three surprising myths to why strategy execution fails

[4]. http://onstrategyhq.com/resources/three-surprising-myths-to-why-strategy-execution-fails/ (Retrieved on 03.07.15)

[5]. Chisaka, B. C. (2007). Ability streaming: a stumbling block to teaching and learning. University of Zimbabwe.

[6]. Dunlop, A., Firth, V and Lurie, R (2013). Dynamic strategy implementation

[7]. http://dupress.com/articles/dynamic-strategy-implementation-delivering-on-your-strategic-ambition/ (Retrieved on 03.07.15)

[8]. Favaro, K., Hirsh, E and Rangan, K (2015). Strategy or Execution: Which Is More Important?

[9]. http://www.strategy-business.com/article/cs00005?gko=733e9 (Retrieved on 03.07.15)

[10]. Blue Ocean Strategy (2015).Four Hurdles to Execution

[11]. https://www.blueoceanstrategy.com/tools/4-hurdles-to-execution/ (Retrieved on 03.07.15)

[12]. Heathfield, S (2015). Use Strategic Planning to Provide Direction humanresources.about.com/bio/Susan-M-Heathfield-6061.htm $(24.10 .15)$ 
[13]. Hrebiniak, L.G (2014). Making Strategy Work: Leading Effective Execution and Change.

[14]. http://www.entrepreneur.com/article/237005 (Retrieved on 28.10.15)

[15]. Kilic, M and Atkuna, A (2015). Perceptions on the obstacles of strategy execution: the case of Turkish Public Organizations. In Hacettepe university journal of economics and administrative sciences. Vol. 33, Issue 1

[16]. Murray, A (2015). What are the Keys to Good Execution? In The Wall Street Journal Guide to Managemen. Published by Harper Business.

[17]. http://guides.wsj.com/management/execution/what-are-the-keys-to-good-execution/ (Retrieved on 03.07.15)

[18]. Yin, R.K. (2009). Case study research. Design and methods. Thousand Oaks: Sage.

[19]. http://www.txstate.edu/about/mission (05.10.15) 